\author{
Andressa Galli, Djenaine De Souza, Gustavo S. Garbellini, Cláudia F. B. Coutinho, Luiz H. Mazo, Luis A. Avaca e \\ Sergio A. S. Machado* \\ Instituto de Química de São Carlos, Universidade de São Paulo, CP 780, 13560-970 São Carlos - SP
}

Recebido em 24/11/04; aceito em 4/5/05; publicado na web em 24/8/05

\begin{abstract}
ELECTROANALYTICAL TECHNIQUES FOR THE DETERMINATION OF PESTICIDES IN FOODS. The aim of this work is to discuss selected applications of electroanalytical techniques for the detection of pesticides in foods and beverages, published in the last ten years. The applications involved different working electrodes for the electroanalytical determination of pesticides, namely amperometric biosensors, cholinesterase-based biosensors, polymer-modified electrodes, ultramicroelectrodes and hanging mercury drop electrodes. They were used for several voltammetric and amperometric techniques in different analytical procedures for the detection and quantification of different classes of pesticides in different food matrices.
\end{abstract}

Keywords: pesticides; electroanalytical methods; foods.

\section{CONSIDERAÇÕES GERAIS}

De acordo com a União Internacional de Química Pura e Aplicada (IUPAC) ${ }^{1}$, pesticidas são substâncias ou mistura de substâncias utilizadas na produção, colheita ou no armazenamento de alimentos. Eles são bioativos e capazes de prevenir, destruir ou combater espécies indesejáveis que, de alguma maneira, possam interferir na produção, no processamento, armazenamento, transporte e estocagem de alimentos, produtos agrícolas em geral, madeira e produtos derivados de madeira.

Esta definição também compreende substâncias utilizadas no combate a insetos domésticos ou quaisquer agentes preventivos à ação de vetores de doenças que possam ser transmitidas ao homem ou animais domésticos como, por ex., febre amarela, doença de Chagas, malária, entre outras. Substâncias usadas como reguladoras no crescimento de plantas, agentes desfolheantes e dessecantes também são denominadas pesticidas.

Existem registros de diferentes substâncias utilizadas como pesticida desde a Antiguidade, tal como piretro de origem natural. No entanto, o uso moderno de pesticidas é datado do século passado, onde substâncias inorgânicas como aceto arsenito de sódio, conhecido como "verde Paris", fluoreto de cálcio, fluorsilicato de cálcio, arseniato de sódio, arsênio branco, entre outras, foram intensamente empregadas ${ }^{2}$.

A partir da década de 30, o aumento da produção agrícola e, principalmente, a diversidade de culturas impuseram a utilização de outras substâncias com melhor poder pesticida. Um grande número de substâncias foram formuladas especialmente para uso na agricultura, no entanto, o fator determinante para o aumento na produção de pesticidas foi a descoberta do DDT [1,1,1-tricloro-2-bis-(pclorofenila)-etano], um organoclorado com alto poder inseticida que foi desenvolvido durante a Segunda Guerra Mundial (1939) ${ }^{2}$.

Existem cerca de 600 ingredientes ativos, utilizados na formulação de pesticidas, registrados para uso específico na agricultura. Destes, 350 contribuem com $98 \%$ dos pesticidas mais utilizados, sendo que $80 \%$ deles são rotineiramente usados na agricultura de países da América do Sul, como o Brasil ${ }^{3,4}$.

*e-mail: sasmach@iqsc.usp.br
Todos estes pesticidas compreendem uma larga variedade de substâncias químicas com diferentes grupos funcionais e, conseqüentemente, com diferentes modos de ação, biotransformação e eliminação. Algumas classes químicas são compostas por organoclorados, carbamatos, organofosforados, piretróides, derivados de uréia, bipiridílios e nitrocompostos, sendo que alguns deles podem causar riscos à saúde e ao meio ambiente 5 .

Dados estatísticos recentes mostram que a produção mundial de pesticidas cresce intensamente ano a ano, colocando o Brasil como o oitavo maior consumidor do mundo. De acordo com um estudo realizado pelo Sindicato Nacional da Indústria de Produtos para Defesa Agrícola (SINDAG), somente no ano de 2003 foram gastos 3,136 bilhões de dólares na comercialização de pesticidas no país, o que corresponde a 160,1 mil t lançadas ao meio ambiente. A maior parte deste consumo corresponde à aquisição de fungicidas, que são muito utilizados nas plantações de soja e representam dois terços da quantidade total ${ }^{6}$.

Atualmente, muitos pesticidas, principalmente da classe dos organoclorados e organofosforados que são as mais tóxicas existentes, tiveram seu uso proibido devido à possibilidade de suas fórmulas favorecerem a formação de tumores cancerígenos, assim como vários outros problemas à saúde humana. Com isto, o desenvolvimento de técnicas precisas de quantificação de resíduos de diferentes pesticidas em águas e alimentos tornou-se de fundamental importância.

Muitos estudos têm sido realizados nos últimos anos com o intuito de se desenvolver metodologias de análise mais precisas e que também possam ser realizadas com tempo e custo inferiores. Além disso, estes estudos visam estabelecer curvas de degradação e limites máximos de resíduos em diferentes amostras?

\section{METODOLOGIAS EMPREGADAS NA ANÁLISE DE PESTICIDAS}

A análise de resíduos de pesticidas, nos mais diferentes meios, é tradicionalmente realizada utilizando-se técnicas cromatográficas. Estas técnicas são muito importantes na análise química em função de sua facilidade em efetuar as separações, identificar e quantificar as espécies presentes na amostra, 
por meio da utilização de detectores específicos.

A quantificação das amostras pode ser realizada com a utilização de detectores cromatográficos, tais como detector por captura de elétrons ${ }^{8}$, fluorescência ${ }^{9}$, ultravioleta-visível ${ }^{10}$, ionização de cha$\mathrm{ma}^{11}$. Estas técnicas também podem ser utilizadas em conjunto com outras, como as espectroscópicas ${ }^{12}$ e eletroanalíticas ${ }^{13,14}$.

As aplicações das técnicas cromatográficas cresceram intensamente nos últimos 50 anos; isto se deve não somente ao desenvolvimento de novos tipos de técnicas de preparação, separação e detecção, mas também pela necessidade crescente de técnicas mais precisas e sensíveis para caracterização e quantificação de analitos de interesse em matrizes complexas, tais como águas naturais, solos, alimentos, sangue, urina e outros tipos de fluidos biológicos ${ }^{15}$.

Estas técnicas apresentam-se como uma excelente ferramenta de separação, com informações quantitativas úteis sobre as espécies separadas. Contudo, a quantidade de informações obtidas com a análise dos cromatogramas é pequena, se comparada com a quantidade fornecida por um único espectro de infravermelho, ressonância magnética nuclear e espectroscopia de massa ${ }^{15}$.

A quantificação de compostos orgânicos utilizando técnicas cromatográficas fornece resultados com limites de detecção na faixa de nanogramas a microgramas/ $\mathrm{L}$ (ng $\mathrm{L}^{-1}$ a $\mu \mathrm{g} \mathrm{L}^{-1}$ ), dependendo do detector utilizado e da técnica de extração. Contudo, são técnicas que dependem de um longo tempo nas etapas iniciais para preparação das amostras, utilizam maior quantidade de reagentes e a instrumentação geralmente é mais dispendiosa financeiramente, o que eleva o custo final das análises. Com isto, há necessidade de se desenvolver técnicas mais rápidas, mais baratas e tão sensíveis quanto as técnicas cromatográficas ${ }^{13}$.

Em 1970, Hance ${ }^{16}$ foi o pioneiro na utilização de técnicas eletroanalíticas na análise de resíduos de pesticidas em águas. Nesse trabalho foi estudado o comportamento eletroquímico de 35 herbicidas em 5 eletrólitos suporte diferentes, utilizando a polarografia derivativa e observou-se que, destes, 28 apresentaram eletroatividade em algum dos eletrólitos usados. Com a resposta eletroativa foi possível construir curvas de trabalho e, assim, detectar a presença de pesticidas em amostras de águas.

As técnicas eletroanalíticas relacionam medidas de quantidades elétricas, tais como, corrente, potencial e carga, com parâmetros químicos ${ }^{17,18}$. Estas apresentam algumas vantagens frente às técnicas tradicionais. A principal delas é a possibilidade, na maioria das vezes, de análise direta da amostra, sem a necessidade de etapa de separação ou pré-tratamento. Além disto, a aplicação de métodos eletroanalíticos possibilita a análise em materiais coloridos ou com partículas sólidas dispersas. A análise direta é, analiticamente, muito conveniente já que o uso de técnicas espectroscópicas e métodos ópticos, na maioria das vezes, requerem separações preliminares.

A aplicação de técnicas eletroanalíticas na análise de amostras complexas, tais como amostras biológicas e ambientais, algumas vezes, requerem etapas de separações químicas, contudo, estas são mais simplificadas, de menor custo e menor tempo, quando comparadas às metodologias de preparação para aplicação de detecção cromatográfica $^{15,19,20}$.

Em geral, as respostas obtidas com a utilização de técnicas eletroanalíticas sofrem uma menor influência de interferentes presentes nas amostras, comparando-se com técnicas cromatográficas, o que tem possibilitado o uso destas técnicas na análise de pesticidas $^{21-26}$.

Atualmente, a sensibilidade das técnicas eletroanalíticas é comparada à de qualquer técnica cromatográfica e espectroscópica. Esta comparação é possível graças ao desenvolvimento tecnológico, o qual possibilitou um grande avanço da instrumentação eletroanalítica, contribuindo intensamente na melhoria da sensibilidade ${ }^{25}$.
A utilização de técnicas eletroanalíticas possibilita estudos de processos de degradação de pesticidas e avaliação dos mecanismos de redução e/ou oxidação eletroquímica, permitindo verificar a formação de produtos intermediários tóxicos, ao homem e ao ambiente ${ }^{25}$.

\section{TÉCNICAS ELETROANALÍTICAS}

As informações obtidas com o uso de técnicas eletroanalíticas são dependentes da superfície eletródica, que deve apresentar elevada razão sinal-ruído e boa reprodutibilidade. O eletrodo de trabalho a ser utilizado depende de dois fatores: do comportamento redox do analito e das correntes residuais obtidas no intervalo de potencial avaliado. Também se deve considerar a janela de potencial de trabalho, condutividade elétrica, reprodutibilidade da superfície, as propriedades mecânicas, o custo de fabricação, a disponibilidade e toxicidade ${ }^{27}$.

A importância da escolha do material do eletrodo de trabalho também se deve ao fato de que as respostas obtidas são relacionadas às reações redox que ocorrem em sua superfície ou na interface eletrodo-solução. Desta forma, o analito de interesse pode interagir com a superfície eletródica, resultando na transferência de elétrons. Entretanto, se a transferência é muito lenta, não ocorre, ou ocorre em um valor de potencial fora da janela de potencial do eletrodo, é possível realizar uma modificação na superfície eletródica a fim de melhorar a resposta final, onde o analito irá interagir diretamente com o agente modificante.

Em 1925, Heyrovsky ${ }^{28}$ iniciou o desenvolvimento de eletrodos de mercúrio para detecções eletroquímicas. Este eletrodo consistia em um reservatório elevado de mercúrio, onde a altura deste reservatório controlava o tamanho e a velocidade de desprendimento da gota, que era usada como eletrodo de trabalho. Com este trabalho, em 1950, recebeu o Prêmio Nobel de Química, pois a partir deste poço de mercúrio desenvolveu-se a polarografia de corrente direta.

Este eletrodo apresentava algumas vantagens, as quais, ainda hoje, são responsáveis pela intensa utilização de eletrodos de mercúrio. A renovação da gota a cada potencial aplicado é uma delas, e é de fundamental importância, já que evita problemas de contaminação e envenenamento do eletrodo ${ }^{29}$. Outra vantagem é a reprodutibilidade no tamanho da gota, pois se não há mudanças em seu tamanho, não há modificação nas respostas de corrente ${ }^{15}$. $\mathrm{O}$ sobrepotencial de evolução de hidrogênio, onde se inicia a decomposição da água, é outra vantagem, já que possibilita medidas em vários meios em uma ampla faixa de potencial.

Todas estas vantagens tornaram o eletrodo de mercúrio o mais versátil e utilizado para detecção de pesticidas em diferentes matrizes. Entretanto, ele é limitado para o intervalo de potenciais positivos, além de ser um metal de elevada toxicidade ${ }^{30}$. Esta limitação do intervalo de potenciais exclui sua utilização no monitoramento de compostos oxidáveis. Assim, eletrodos sólidos que possuem uma janela de potencial positiva têm considerável aplicabilidade em determinações analíticas. Alguns materiais que podem ser utilizados para construção de eletrodos sólidos são platina, ouro, carbono, irídio, ródio, paládio, níquel, ferro, cobre e tungstênio.

As respostas obtidas com a utilização destes eletrodos são dependentes das condições da superfície eletródica. Assim, o uso de tais eletrodos requer um minucioso pré-tratamento eletroquímico e/ou polimento mecânico para obtenção de resultados reprodutíveis. A natureza das etapas de pré-tratamento depende dos tipos de materiais envolvidos na construção dos eletrodos. Polimentos mecânicos e ciclagem de potenciais são comumente utilizados para eletrodos metálicos, onde vários tratamentos químicos, eletroquímicos ou térmicos podem ser usados para ativa- 
ção das superfícies eletródicas ${ }^{27}$.

O desenvolvimento da parte eletrônica da instrumentação utilizada em eletroanalítica, principalmente nas medidas de correntes muito pequenas, e o surgimento de materiais com estruturas micrométricas proporcionaram as ferramentas necessárias à miniaturização dos eletrodos de trabalho, possibilitando a utilização de ultramicroeletrodos (UMEs) em diferentes meios.

A utilização de UMEs promove um aumento na qualidade dos dados experimentais. Estes incluem melhor resolução do perfil voltamétrico, maior densidade de corrente e diminuição nos efeitos da resistência da solução ${ }^{31}$. Além disto, UMEs podem ser utilizados para investigar uma larga variedade de experimentos em diversos sistemas antes impossíveis com eletrodos convencionais, tais como análises in vivo ${ }^{32}$. Adicionalmente, o uso de UMEs possibilita determinações de diferentes pesticidas diretamente nas amostras, sem necessidade de tratamentos prévios ${ }^{33}$, na ausência de eletrólito suporte e utilizando altas velocidades de varredura ${ }^{34,35}$. Os UMEs podem ser construídos com diferentes tipos de metais e ainda podem servir de suporte para modificação com mercúrio, polímeros e enzimas ${ }^{36-38}$.

Se o analito de interesse não interage com o eletrodo, é possível realizar uma modificação na superfície eletródica pela imobilização de grupos funcionais, incorporação de catalisadores inorgânicos e biológicos (enzimas e anticorpos), deposição de filmes poliméricos, modificação com sílica e deposição de membranas biológicas ${ }^{39}$. Estes eletrodos, chamados de eletrodos quimicamente modificados, são mais seletivos e mais sensíveis, pois a modificação possibilita controlar a natureza físico-química da interface eletrodo-solução como uma forma de alterar a reatividade e seletividade do eletrodo base favorecendo, assim, o desenvolvimento de eletrodos para diferentes aplicações analíticas ${ }^{40}$.

As modificações de superfícies eletródicas são importantes, uma vez que são específicas a um determinado tipo de analito e promovem um alto grau de seletividade, possibilitando o desenvolvimento de sensores de fácil manipulação e construção, baixo custo, potencial de miniaturização e detecção rápida ${ }^{41}$. Desta forma, a utilização de agentes modificantes representa uma alternativa à substituição de eletrodos de mercúrio e metais inertes.

A construção de biossensores é baseada na inibição da atividade de enzimas específicas, que são freqüentemente empregadas na detecção de pesticidas organofosforados e carbamatos ${ }^{42}$. A utilização de eletrodos modificados com materiais de interesse biológico, tais como a imobilização de microorganismos vivos, também tem sido relatada para determinação de resíduos de pesticidas organofosforados, nas quais as respostas obtidas são função da atividade respiratória do microorganismo ${ }^{43}$.

\section{DETERMINAÇAO DE PESTICIDAS EM ALIMENTOS}

O aumento da poluição ambiental por metais tóxicos e principalmente por resíduos de pesticidas, das mais variadas classes químicas, tem estimulado o desenvolvimento de técnicas apropriadas para avaliação destes compostos em diferentes tipos de alimentos e bebidas em geral, pois estes são os principais caminhos de ingestão destes contaminantes pelo homem ${ }^{44}$.

Um grande número de trabalhos sobre determinação eletroanalítica de pesticidas em alimentos, in natura ou industrializados tem sido publicado nos últimos anos, sendo que a maior parte corresponde à utilização de eletrodos modificados com enzimas e eletrodos de mercúrio.

As principais técnicas de detecção eletroquímica utilizadas são voltametria de onda quadrada, voltametria de pulso diferencial, voltametria de pulso normal, amperometria, potenciometria e condutimetria ${ }^{45}$.
Os pesticidas apresentam diferentes grupos eletroativos, os quais definem o material do eletrodo de trabalho que será utilizado no desenvolvimento da metodologia de análise. A seguir, são apresentados alguns trabalhos da literatura, que relatam a determinação de pesticidas em alimentos e bebidas.

\section{Pesticidas triazínicos}

As triazinas são utilizadas como herbicidas no controle pré e pós-emergente de ervas daninhas nas mais variadas culturas, desde a década de 50. Os herbicidas pertencentes a este grupo compreendem cerca de $30 \%$ da produção mundial ${ }^{46}$. As s-triazinas, normalmente possuem um anel heterocíclico de seis membros onde os átomos de $\mathrm{C}$ e $\mathrm{N}$ são simetricamente localizados e os substituintes das posições 2, 4 e 6, constituem-se no diferencial entre as várias formulações disponíveis comercialmente ${ }^{47}$.

A maior parte dos trabalhos envolvendo determinação eletroanalítica das triazinas relatam a detecção utilizando eletrodos de mercúrio. Como reportado, as triazinas apresentam um ou mais picos referentes à redução das formas mono- e di- protonadas, picos estes que podem ser utilizados para determinação eletroanalítica de triazinas em diferentes amostras ${ }^{17}$. Os limites de detecção obtidos variam de acordo com a técnica utilizada ${ }^{48-51}$.

A análise de triazinas em alimentos utilizando-se eletrodos de mercúrio é pouco explorada, principalmente em função de sua forte adsorção na superfície eletródica. Neste sentido, Pedrero e colaboradores ${ }^{52}$ utilizaram um surfactante aniônico a fim de inibir este processo adsortivo e desenvolver uma metodologia para determinação de desmetrina em amostras de sucos de maçã, utilizando a voltametria de pulso diferencial. Após etapas de separação e "clean up", utilizando coluna $\mathrm{C}_{18}$, foi obtido limite de detecção de $1,0 \times 10^{-8} \mathrm{~mol} \mathrm{~L}^{-1}$.

Yulaev e colaboradores ${ }^{53}$ utilizaram um biossensor potenciométrico com enzima peroxidase para detecção de simazina em alimentos. Este biossensor foi baseado na detecção potenciométrica da água oxigenada gerada pela reação da enzima peroxidase com o substrato, que é inibida após a reação competitiva com o pesticida. O mecanismo de resposta do biossensor é função da reação competitiva entre a simazina e o substrato pelos sítios ativos da enzima diminuindo, assim, a formação do produto da reação entre substrato e enzima. Neste trabalho, a superfície que apresentou melhor eficiência como suporte para o biossensor foi o ouro. Deste modo, o eletrodo modificado foi utilizado para detecção de simazina em carne, pepino, tomate, batata, leite e sucos de frutas. Os resultados obtidos mostraram-se convenientes para detecção em alimentos, minimizando o tempo de análise.

\section{Pesticidas organofosforados}

Os pesticidas organofosforados possuem em sua estrutura um átomo central de fósforo pentavalente ligado a um átomo de oxigênio ou enxofre, por uma dupla ligação. Estes são menos persistentes no ambiente que os organoclorados, contudo, possuem efeito tóxico mais agudo para seres humanos e outros mamíferos, pois são inibidores da enzima acetilcolinesterase, essencial para a transmissão de impulsos nervosos ${ }^{30}$. Tais como os organoclorados, os organofosforados são lipossolúveis, sendo contaminantes potenciais para diversos tipos de alimentos.

A eletroatividade dos pesticidas organofosforados está intimamente relacionada à estrutura química do pesticida. Alguns organofosforados apresentam respostas eletroativas sobre superfície de mercúrio, como, por ex., monocrotofós, fosfamidom, diclorvos, fenitrotiona, fentiona, dentre outros. Em geral, estes apresentam processo redox bem definido em meio ácido, alcalino ou 
neutro, que é atribuído à redução da dupla ligação carbono-carbono em cada um dos compostos e/ou à redução de íons cloreto ou grupo nitro presentes na estrutura do composto ${ }^{45}$.

Em função das respostas eletroativas obtidas sobre mercúrio, alguns trabalhos apresentam a determinação eletroanalítica de organofosforados em cereais ${ }^{54}$, utilizando-se a polarografia de pulso diferencial no desenvolvimento de uma metodologia para determinação de resíduos de dicrotofós, crotoxifós e clorofenvinfós. Os resultados obtidos mostraram boa precisão e reprodutibilidade da metodologia.

O ultramicroeletrodo de ouro foi utilizado por De Souza e Machado $^{55}$ para determinação eletroanalítica de diclorvos em leite de vaca. Os resultados mostraram que o ultramicroeletrodo apresentou um desempenho satisfatório, possibilitando a obtenção de limites de detecção baixos o suficiente para sua aplicação em alimentos, apontando para a possibilidade de substituição de eletrodos de mercúrio por eletrodos sólidos, minimizando a geração de resíduos tóxicos de mercúrio.

Como os organofosforados são inibidores da enzima acetilcolinesterase, esta é utilizada para desenvolvimento de eletrodos modificados. Os estudos são baseados no efeito da inibição da enzima pela presença do pesticida organofosforado. A técnica aplicada quando estes tipos de eletrodos são utilizados, geralmente, é a detecção potenciométrica, que possibilita a quantificação de uma ampla variedade de pesticidas organofosforados em alimen$\operatorname{tos}^{56,57}$ e bebidas ${ }^{58,59}$, devido à sua alta eficiência e seletividade.

\section{Nitropesticidas}

Estes pesticidas apresentam em sua estrutura o grupo nitro e, normalmente, são muito tóxicos. Em geral, fornecem respostas eletroativas sobre superfície de mercúrio, onde o mecanismo de redução forma o intermediário hidroxilamina, formando como produtos finais diferentes aminas. Os principais nitropesticidas são divididos em quatro grupos básicos: nitrorganofosforados, derivados de nitrofenol, derivados de dinitroanilinas e nitrorganoclorados ${ }^{45}$.

O principal representante desta classe é o metil paration, um nitrorganofosforado inibidor da enzima acetilcolinesterase. Assim, vários trabalhos foram desenvolvidos utilizando eletrodos modificados com enzimas para a determinação deste pesticida em ali$\operatorname{mentos}^{52,59,60}$.

Um exemplo de dinitroanilina determinada em alimentos é a trifluralina. Hegedüs e colaboradores ${ }^{61}$ utilizaram um biossensor para detecção deste herbicida em amostras de sucos de cenoura, abóbora e tomate.

O p-nitrofenol, um derivado do nitrofenol, é um metabólito de vários pesticidas organofosforados. Desta forma, algumas metodologias eletroanalíticas têm sido implementadas para determinação de seus resíduos em diferentes tipos de amostras. Neste contexto, Calvo-Marzal e colaboradores ${ }^{62}$ avaliaram resíduos de p-nitrofenol utilizando eletrodo de carbono vítreo recoberto com membrana de Nafion ${ }^{\circledR}$, em função da atividade da enzima fosfatase ácida em solução. Os resultados mostraram que a inibição da atividade da enzima está relacionada com a concentração do pesticida, os limites de detecção obtidos com eletrodo modificado com Nafion ${ }^{\circledR}$ foram menores que os obtidos com o eletrodo de carbono vítreo liso, e, ainda, possibilitaram a quantificação de p-nitrofenol em amostras de feijão.

\section{Pesticidas organoclorados}

Os pesticidas organoclorados são extremamente tóxicos e apresentam elevada estabilidade e capacidade de bio-acumulação, podendo gerar problemas de saúde e ambientais. O mecanismo redox destes pesticidas geralmente envolve a remoção de um átomo de cloro. Os limites de detecção obtidos com a utilização de técnicas eletroanalíticas são relacionados à presença de anel benzênico e de duplas ligações nas estruturas dos compostos ${ }^{17}$.

Em geral, estes adsorvem fortemente na superfície eletródica, prejudicando, assim, a sensibilidade e reprodutibilidade analíticas. Desta forma, alguns estudos eletroanalíticos são realizados em soluções micelares (surfactantes catiônicos e aniônicos) ou misturas com solventes orgânicos. Neste contexto, Reviejo e colaboradores $^{63}$ utilizaram polarografia de pulso diferencial na determinação de dieldrin, $\alpha$-endosulfan, $\beta$-endosulfan, endosulfan-sulfato e heptacloro, em amostras de maçãs, onde os limites de detecção apresentaram valores elevados $\left(10^{-6} \mathrm{~mol} \mathrm{~L}^{-1}\right)$ indicando uma baixa sensibilidade quando comparados a outras classes de pesticidas, entretanto, apontam a possibilidade de utilização de técnicas eletroanalíticas na determinação qualitativa de organoclorados.

\section{Pesticidas bipiridílios}

Os pesticidas bipiridílios apresentam intenso uso na agricultura. São compostos diquartenários nitrogenados e estruturalmente são cátions bivalentes altamente solúveis, estáveis na presença de luz e calor e inativos no solo. Estes compostos são extremamente tóxicos ao meio ambiente e à saúde humana, apesar disto são, atualmente, os herbicidas mais empregados em cerca de 130 países, inclusive no Brasil.

O principal representante da classe dos bipiridílios é o paraquate, classificado pela Agência de Proteção Ambiental Americana (EPA) como um possível carcinogênico, mas não mutagênico. O diquate é o segundo representante mais importante desta classe e também apresenta as mesmas características tóxicas que o paraquate. Além destes, ainda fazem parte desta classe o difenzoquat e o benzoquat.

$\mathrm{O}$ paraquate e o diquate apresentam respostas eletroativas sobre eletrodos de mercúrio. Walcarius e Lamberts ${ }^{64}$ desenvolveram uma metodologia utilizando voltametria de onda quadrada para determinação de resíduos destes pesticidas em amostras de batatas, obtendo limites de detecção satisfatórios para determinações eletroanalíticas.

De Souza e Machado ${ }^{55}$ utilizaram UMEs de ouro aliados à voltametria de onda quadrada para determinação de paraquate em sucos de laranja e limão. Os resultados obtidos mostraram que é possível o uso direto de ultramicroeletrodos em amostras complexas, sem necessidade de etapas de separação química ou preparação da amostra.

\section{Pesticidas carbamatos}

Os carbamatos são utilizados como inseticidas e herbicidas. Estes compostos são muito instáveis em condições neutras e alcalinas, à temperatura ambiente ${ }^{65}$. O primeiro representante da classe dos carbamatos foi o profam, seguido por outros, como clorprofam, barban, asulam, carbutilato, clorbufam, desmedifam e suepe. Estes compostos são sais ou ésteres do ácido carbônico, com substituições dos hidrogênios hidroxílicos e amínicos, por átomos, grupos funcionais ou radicais ${ }^{66}$.

Alguns carbamatos necessitam de etapas de derivatização para determinação eletroanalítica destes compostos e o desenvolvimento de metodologias que empreguem diferentes superfícies eletródicas, tais como eletrodos sólidos e biossensores.

No caso dos pesticidas carbaril e carbofurano, os principais representantes da classe dos carbamatos, a detecção eletroanalítica só é possível pela determinação dos produtos de hidrólise em meio alcalino ${ }^{67}$.

Diferentes UMEs podem ser empregados para determinação de carbamatos. Assim, metodologias eletroanalíticas foram desen- 
volvidas e aplicadas na determinação de tiram em amostras de uva ${ }^{68}$ e de dissulfiram em amostras de ervilha ${ }^{69}$. O emprego de UMEs possibilitou análise direta nas amostras com melhoras significativas das resposta.

Em geral, os carbamatos são inibidores da enzima acetilcolinesterase $\mathrm{e}^{70}$. Desta maneira, vários trabalhos relatam o uso de eletrodos modificados com enzimas na determinação destes compostos em amostras de alimentos ${ }^{58,71,72}$.

\section{Pesticidas piretróides}

Os piretróides foram originalmente obtidos a partir de compostos de origem natural, tais como piretro, nicotina e ácido crisantêmico. Apesar de possuírem uma menor toxicidade que a maioria das outras classes de pesticidas, podem apresentar uma longa persistência em ambientes fechados, uma vez que são, freqüentemente, utilizados como inseticidas domésticos.

Os piretróides são mais eficientes e seguros, pois são seletivos e não apresentam toxicidade para mamíferos ${ }^{73}$. São largamente empregados em diversos tipos de culturas no controle de insetos, podendo ser eventuais contaminantes em alimentos.

Samatha e Sreedhar ${ }^{68}$ utilizaram polarografia de pulso diferencial no estudo da cinética e do mecanismo de redução da deltametrina.
Desenvolveram, também, metodologia para quantificação deste pesticida em amostras de couve, tomate, arroz e trigo.

\section{Pesticidas sulfoniluréias}

As sulfoniluréias ou feniluréias são herbicidas largamente empregados em diferentes culturas. Geralmente, possuem alta solubilidade em água e baixa capacidade de adsorção no solo ${ }^{74}$. Também apresentam baixa toxicidade, são seletivos e muito eficientes.

A estrutura das sulfoniluréias consiste de três partes distintas: um grupo arila, uma ponte sulfoniluréia e um anel heterocíclico contendo nitrogênio. O comportamento eletroanalítico destes compostos é dependente do $\mathrm{pH}$ do meio e os poucos trabalhos publicados indicam que as melhores respostas voltamétricas são obtidas em meio ácido ${ }^{45}$.

Pulido-Tofiño e colaboradores ${ }^{75,76}$ desenvolveram biossensores utilizando anticorpos encapsulados em matriz sol-gel, para determinação de isoproturon. O uso deste eletrodo promoveu maior seletividade, possibilitando a determinação de resíduos do pesticida em amostras de ervilha e batata.

Na Tabela 1 são apresentados alguns trabalhos referentes à determinação de pesticidas em amostras de alimentos, utilizando-se técnicas eletroanalíticas aliadas a diferentes eletrodos de trabalho, bem como os valores de limites de detecção (LD).

Tabela 1. Resumo das aplicações de técnicas eletroanalíticas na determinação de pesticidas em alimentos

\begin{tabular}{|c|c|c|c|c|}
\hline Pesticida & Eletrodo de trabalho & Matriz & LD & Ref. \\
\hline Simazina (triazina) & biossensor & $\begin{array}{l}\text { carne, pepino,tomate, batata, } \\
\text { leite e sucos de frutas }\end{array}$ & NR & 53 \\
\hline Atrazina (triazina) & biossensor & milho & $0,50 \mathrm{mg} \mathrm{L}^{-1}$ & 77 \\
\hline $\begin{array}{l}\text { Aldicarbe, carbaril, } \\
\text { carbofurano, metomil e } \\
\text { propoxur (N-metilcarbamatos) }\end{array}$ & biossensor & $\begin{array}{l}\text { batata, cenoura } \\
\text { e pimenta doce }\end{array}$ & 1,00 a $3,50 \times 10^{-4} \mathrm{mg} \mathrm{kg}^{-1}$ & 72 \\
\hline
\end{tabular}

\begin{tabular}{|c|c|c|c|c|}
\hline Paraquate e diquate (bipiridílios) & HMDE & batata & $1,50 \times 10^{-8} \mathrm{~mol} \mathrm{~L}^{-1}$ & 65 \\
\hline Paraquate (bipiridílio) & UME de $\mathrm{Au}$ & sucos de laranja e limão & NR & 33 \\
\hline $\begin{array}{l}\text { Dieldrin, } \alpha \text {-endosulfan, } \\
\beta \text {-endosulfan, endosulfan } \\
\text { sulfato, heptacloro } \\
\text { (organoclorados) }\end{array}$ & HMDE & maçãs & $1,00 \times 10^{-6} \mathrm{~mol} \mathrm{~L}^{-1}$ & 63 \\
\hline $\begin{array}{l}\text { Clorofenvinpós, } \\
\text { dicrotofós e crotoxyfos } \\
\text { (organofosforados) }\end{array}$ & DME & cereais & $0,35 \mu \mathrm{g} \mathrm{L}-1$ & 54 \\
\hline $\begin{array}{l}\text { Carbaril e carbofurano } \\
\text { (carbamatos) }\end{array}$ & carbono vítreo & vegetais & $0,10 \mathrm{mg} \mathrm{L}^{-1}$ & 67 \\
\hline Carbaril (carbamato) & biossensor & kiwi & $0,20 \mu \mathrm{g} \mathrm{L}^{-1}$ & 78 \\
\hline Dinoseb (feniluréia) & filme de mercúrio & suco de maçã & NR & 79 \\
\hline Tiram (carbamato) & grafite modificado & morango & $12,9 \mu \mathrm{g} \mathrm{L} \mathrm{L}^{-1}$ & 80 \\
\hline Paraoxon (organofosforado) & biossensor & kiwi & $0,28 \mu \mathrm{g} \mathrm{L}{ }^{-1}$ & 71 \\
\hline $\begin{array}{l}\text { Promecarbe e propoxur } \\
\text { (carbamato) }\end{array}$ & carbono vítreo & vegetais & $0,10 \mathrm{mg} \mathrm{L}^{-1}$ & 67 \\
\hline Cianopiretróide & HMDE & cereais & $1,00 \mathrm{mg} \mathrm{L}^{-1}$ & 72 \\
\hline Paraoxon (organofosforado) & biossensor & suco de laranja & $9,50 \mu \mathrm{g} \mathrm{L}-1$ & 58 \\
\hline Paraoxon (organofosforado) & biossensor & alimento infantil & $<5,00 \mathrm{mg} \mathrm{L}^{-1}$ & 56 \\
\hline Fenitrotiona (organofosforado) & biossensor & alface e arroz & $0,50 \mathrm{ng} \mathrm{mL}^{-1}$ & 57 \\
\hline
\end{tabular}


Tabela 1. continuação

\begin{tabular}{|c|c|c|c|c|}
\hline Pesticida & Eletrodo de trabalho & Matriz & LD & Ref. \\
\hline Fentiona (organofosforado) & biossensor & alface e arroz & $0,50 \mathrm{ng} \mathrm{mL}^{-1}$ & 82 \\
\hline Tiram (carbamato) & UME de fibra de carbono & uva & $4,30 \times 10^{-7} \mathrm{~mol} \mathrm{~L}^{-1}$ & 65 \\
\hline Tiram (carbamato) & biossensor & alface & 5,00 a $40,00 \mathrm{ng} \mathrm{mL}^{-1}$ & 83 \\
\hline $\begin{array}{l}\text { Atrazina, ametrina e simazina } \\
\text { (triazinas) }\end{array}$ & biossensor & suco e leite & NR & 84 \\
\hline Atrazina (triazina) & biossensor & sucos de frutas & $2,10 \mu \mathrm{g} \mathrm{L}^{-1}$ & 85 \\
\hline Desmetrina (triazina) & HMDE & suco de maçã & $2,40 \times 10^{-9}$ a $8,10 \times 10^{-10} \mathrm{~mol} \mathrm{~L}^{-1}$ & 52 \\
\hline Carbaril (carbamato) & biossensor & ovo, carne bovina, leite, mel & 2,00 a $1,00 \mathrm{ng} \mathrm{mL}^{-1}$ & 86 \\
\hline Metil paration (nitrocomposto) & biossensor & ovo, carne bovina, leite, mel & 2,00 a $1,00 \mathrm{ng} \mathrm{mL}^{-1}$ & 86 \\
\hline Carbofurano (carbamato) & biossensor & sucos de maçã, uva, abacaxi & $0,20 \mathrm{ng} \mathrm{mL}^{-1}$ & 87 \\
\hline Paraoxon (organofosforado) & biossensor & sucos de uva e laranja & $1,00 \times 10^{-10}$ a $1,00 \times 10^{-11} \mathrm{~mol} \mathrm{~L}^{-1}$ & 58 \\
\hline Carbofurano (carbamato) & biossensor & sucos de uva e laranja & $1,00 \times 10^{-10}$ a $1,00 \times 10^{-11} \mathrm{~mol} \mathrm{~L}^{-1}$ & 58 \\
\hline $\begin{array}{l}\text { Paraoxon, clorpirifós e diazinona } \\
\text { (organofosforados) }\end{array}$ & biossensor & suco de frutas & $1,00 \mathrm{ng} \mathrm{mL}^{-1}$ a $4,00 \mu \mathrm{g} \mathrm{mL}^{-1}$ & 59 \\
\hline $\begin{array}{l}\text { Carbaril e carbofurano } \\
\text { (carbamatos) }\end{array}$ & biossensor & suco de frutas & $1,00 \mathrm{ng} \mathrm{mL}^{-1}$ a $4,00 \mu \mathrm{g} \mathrm{mL}^{-1}$ & 59 \\
\hline $\begin{array}{l}\text { Carbofurano e propamocarb } \\
\text { (carbamatos) }\end{array}$ & biossensor & alface, saladas e cebola & NR & 88 \\
\hline $\begin{array}{l}\text { Metil oxidemeton e metil } \\
\text { paration (nitropesticidas) }\end{array}$ & biossensor & alface, saladas e cebola & NR & 88 \\
\hline $\begin{array}{l}\text { Aldicarbe, carbaril, carbofurano, } \\
\text { metomil e propoxur (carbamatos) }\end{array}$ & biossensor & frutas e vegetais & NR & 89 \\
\hline Carbaril (carbamatos) & biossensor & $\begin{array}{l}\text { banana, cenoura, laranja, } \\
\text { batata e feijão verde }\end{array}$ & 2,70 a $5,70 \mu \mathrm{g} \mathrm{L}^{-1}$ & 90 \\
\hline Dissulfiram (carbamato) & UME de Au & ervilha & $6,30 \times 10^{-8} \mathrm{~mol} \mathrm{~L}^{-1}$ & 69 \\
\hline 4'-DDT (organoclorado) & biossensor & alimento infantil industrializado & 0,30 a $110,00 \mu \mathrm{g} \mathrm{L}^{-1}$ & 91 \\
\hline $\begin{array}{l}\text { Malationa, clorpirifós } \\
\text { (organofosforados) }\end{array}$ & biossensor & alimento infantil industrializado & 0,30 a $110,00 \mu \mathrm{g} \mathrm{L}^{-1}$ & 91 \\
\hline $\begin{array}{l}\text { Atrazina (triazina), } \\
\text { carbofurano (carbamato), } \\
\text { metacloro, clorpirifós } \\
\text { (organofosforados) }\end{array}$ & biossensor & alimento infantil industrializado & NR & 92 \\
\hline $\begin{array}{l}\text { Fenitrotiona e clorpirifós } \\
\text { (organofosforado) }\end{array}$ & biossensor & aipo e laranja & $58,00 \mu \mathrm{g} \mathrm{L}^{-1}$ & 93 \\
\hline Metil azinfós (organofosforado) & biossensor & sucos de laranja e maça & $0,40 \mu \mathrm{g} \mathrm{L}^{-1}$ & 94 \\
\hline Metil paration (organofosforado) & biossensor & frutas e vegetais & NR & 60 \\
\hline Trifluralina (nitropesticida) & biossensor & acos de abóbora, cenoura e tomate & NR & 61 \\
\hline Deltametrina (piretróide) & HMDE & couve, tomate, arroz e trigo & NR & 68 \\
\hline
\end{tabular}

$\mathrm{NR}=$ não relatado; HMDE = eletrodo de gota pendente de mercúrio; DME = eletrodo gotejante de mercúrio; UME = ultramicroeletrodo

\section{PERSPECTIVAS}

O aperfeiçoamento das técnicas eletroanalíticas está intimamente relacionado à melhoria da sensibilidade analítica (característica da técnica utilizada) e também da seletividade (relacionada ao material do eletrodo de trabalho). Assim, o desenvolvimento de técnicas rápidas, confiáveis e sensíveis que possam ser utilizadas para detecção de compostos de interesse ambiental, biológico e industrial vem sendo objeto de estudo.
Uma técnica que tem sido aplicada nos últimos anos é a múltipla voltametria de onda quadrada ${ }^{95-97}$, que possibilita a determinação de traços e ultra-traços de espécies orgânicas e inorgânicas, correspondendo a limites de detecção na ordem de $1 \mathrm{ng} \mathrm{L^{-1 }}$ (1 ppt) podendo, assim, ser aplicada com sucesso na detecção de pesticidas em alimentos e bebidas ${ }^{98}$.

Recentemente, moléculas de DNA têm sido incorporadas à superfícies eletródicas para detecção de bactérias ${ }^{99}$, vírus ${ }^{100}$, monitoramento genético de doenças, monitoramento ambiental 
(águas e solos) $^{101}$, de alimentos contaminados por microorganismos patogênicos e também analitos que apresentam afinidade pela molécula de DNA, como por ex.: compostos carcinogênicos e mutagênicos ${ }^{102}$ e drogas ${ }^{103}$. Desta maneira, a modificação de eletrodos com moléculas de DNA poderia promover um aumento na seletividade a pesticidas permitindo, assim, a aplicação em amostras de alimentos e bebidas contaminados.

\section{CONCLUSÕES}

A rapidez, o baixo custo das análises, a facilidade no manuseio da instrumentação e os baixos limites de detecção fazem das técnicas eletroanalíticas uma alternativa extremamente viável às tradicionais técnicas cromatográficas, para detecção de resíduos de pesticidas em alimentos.

Uma desvantagem apresentada pelas técnicas eletroanalíticas é a seletividade eletroquímica, sendo este inconveniente, possivelmente, solucionado com a utilização de eletrodos quimicamente modificados com polímeros, mercúrio, enzimas, moléculas de DNA, etc., que promovem uma melhor seletividade, minimizando a interferência de várias outras substâncias e compostos químicos, presentes em amostras tão complexas, tais como os alimentos.

\section{AGRADECIMENTOS}

Ao CNPq, à CAPES e FAPESP (Proc. No. 03/03256-4, 03/ 12926-3 e 04/00839-1) pelo suporte financeiro.

\section{REFERENCIAS}

1. Holland, P. T.; Pure Appl. Chem. 1996, 62, 1167.

2. Klaassen, C. D.; Toxicology-the basic science of poisons (Casartt \& Doull's), 5ed., International Edition: New York, 1989.

3. Richardson, M.; Water Sci. Technol. 1998, 37, 19.

4. http://www.andef.com.br, acessada em Setembro 2004

5. Unnever, J.; Pingali, P. L.; Zilberman, D.; Food Pol. 1997, 22, 105.

6. http://www.sindag.com.br, acessada em Setembro 2004

7. Giuochon, G. A.; Beaver, L. A.; Anal. Chim. Acta 2004, 524, 1.

8. Suchan, P.; Pulkrabová, J.; Hajslová, J.; Kocourek, V.; Anal. Chim. Acta 2004, 520, 193

9. Nedelkoska, T. V.; Low, G. K. C.; Anal. Chim. Acta 2004, 511, 145.

10. Huang, S. D.; Huang, H. I.; Sung, Y. H.; Talanta 2004, 64, 887.

11. Engelmann, M. D.; Hutcheson, R.; Henschied, K.; Neal, R.; Cheng, F.; Microchem. J. 2003, 74, 19.

12. Jiang, H.; Adams, C. A.; Koffskey, W.; J. Chromatogr., A 2005, 1064, 219

13. Collins, C. H.; Princípios básicos de cromatografia, Ed. Unicamp: Campinas, 1990.

14. Paterson, B.; Cowie, C. E.; Jackson, P. E.; J. Chromatogr., A 1996, 731 95

15. Skoog, D. A.; Holler, F. J.; Nieman, T. A.; Fundamental of Analytical Chemistry, $5^{\text {th }}$. Saunders Golden Sunburst Series: Philadelphia, 1998.

16. Hance, R. J.; Pestic. Sci. 1970, 1, 112.

17. Wang, J.; Analytical Electrochemistry, VCH Publishers: New York, 1994.

18. Vaz, C. M. P.; Crestana, S.; Machado, S. A. S.; Mazo, L. H.; Massaropi, M. R. C.; Avaca, L. A.; Pesticidas: Revista de Ecotoxicologia e Meio Ambiente 1996, 6, 55.

19. Codognoto, L.; Zuin, V. G.; De Souza, D.; Yariwake, J. H.; Machado, S. A. S.; Avaca, L. A.; Microchem. J. 2004, 77, 177.

20. Ripp, E. B.; Zuman, P.; J. Agric. Food Chem. 1992, 40, 2016.

21. Massaroppi, M. R. C.; Machado, S. A. S.; J. Braz. Chem. Soc. 2003, 14 , 113.

22. Tsai, Y. C.; Coles, B. A.; Houte, K.; Foord, J. S.; Marken, F.; Compton, R. G.; Electroanalysis 2001, 13, 831.

23. Oskan, S. A.; Uslu, B.; Anal. Bional. Chem. 2002, 372, 582

24. Yilmaz, S.; Uslu, B.; Oscan, S. A.; Talanta 2001, 54, 351.

25. De Souza, D.; Codognoto, L.; Malagutti, A. R.; Toledo, R. A.; Pedrosa, V. A.; Oliveira, R. T. S.; Mazo, L. H.; Avaca, L. A.; Machado, S. A. S.; Quim. Nova 2004, 27, 790.

26. Smulders, C. J. G. M.; Bueters, T. J. H.; Van Kleef, R. G. D. M.; Vijverberg, H. P. M.; Toxicol. Appl. Pharmacol. 2003, 193, 139.
27. Wang, J.; Stripping Analysis: Principles, Instrumentation and Applications, VCH Publishers: Deerfield Beach, 1985.

28. Dahmen, E. A. M. F.; Electroanalysis (Theory and applications in aqueous and non-aqueous media in automated chemical control), Elsevier: Amsterdam, 1986.

29. Zuman, P.; Microchem. J. 1997, 57, 4.

30. Baird, C.; Environmental Chemistry, $2^{\text {nd }}$., Freeman: Houndmils, 2000.

31. Osteryong. J. Em Microelectrodes: Theory and Applications; Montenegro, M. I.; Queirós, M. A.; Dasbach, J. L., eds.; Applied Sciences: Canadá, 1991.

32. Wightman, R. M.; Wipf, D. O. Em Electroanalytical Chemistry (a series of advances); Bard, A. J., ed.; Marcel Dekker: New York, 1984, vol. 14.

33. De Souza, D.; Machado, S. A. S.; Anal. Chim. Acta 2005, 546, 85.

34. De La Huebra, M. J.; Hernadéz, P.; Nieto, O.; Ballesteros, Y.; Hernadéz, L.; Fresenius J. Anal. Chem. 2000, 367, 474.

35. Zoski, C. G.; Electroanalysis 2002, 14, 1041.

36. Fung, Y. S.; Mak, J. L. L.; Electrochim. Acta 1999, 44, 3855.

37. Zen, J. M.; Chen, I. L.; Shih, Y.; Anal. Chim. Acta 1998, 369, 103.

38. Montgomery, A. L.; Schwarzkopf, S. R.; Ragsdale S. R.; Oleinikov, A. V; Biosens. Bioelectron. 2004, 20, 736 .

39. Murray, R. W. Em ref. 32, vol. 13

40. Pereira, A. C.; Santos, A. S.; Kubota, L. T.; Quim. Nova 2002, 25, 1012

41. Solnà, R.; Sapelnikova, S.; Skládal, P.; Winther-Nielsen, M.; Carlson, C.; Emnéus, J.; Ruzgas, T.; Talanta 2005, 65, 349.

42. Trojanowicz, M.; Hitchman, M.; Trends Anal. Chem. 1996, 15, 38.

43. Guliy, O. I.; Ignatov, O. V.; Makarov, O. E.; Ignatov, V. V.; Biosens. Bioelectron. 2003, 18, 1005 .

44. Tadeu, J. L.; Sánchez-Brunet, C.; Pérez, R. A.; Fernández, M. D.; J. Chromatogr., A 2000, 882, 175.

45. Garrido, E. M.; Delerue-Matos, C.; Lima, J. L. F. C.; Brett, A. M. O.; Anal. Lett. 2004, 37, 1755.

46. Cabral, M. F.; De Souza, D.; Alves, C. R.; Machado, S. A. S.; Eclet. Quim. 2003, 28, 41

47. Pacáková, V.; Jiskra, J.; J. Chromatogr., A 1996, 754, 17.

48. Caetano, J.; Homem-de-Melo, P.; da Silva, A. B. F.; Ferreira, A. G.; Avaca, L. A.; J. Am. Chem. Soc., submetido.

49. Anh, T. M.; Dzyadevych, S. V.; Van, M. C.; Renault, N. J.; Duc, C. N.; Chovelon, J. M.; Talanta 2004, 63, 365.

50. Grennan, K.; Strachan, G.; Porter, A. J.; Killard, A. J.; Smyth, M. R.; Anal. Chim. Acta 2003, 500, 287.

51. Vaz, C. M. P.; Crestana, S.; Machado, S. A. S.; Mazo, L. H.; Avaca, L. A.; Electroanalysis 1997, 9, 956

52. Pedrero, M.; Galvez, R.; Rodriguez, E.; Manuel de Villena, F. J.; Pingarrón, J. M.; Talanta 2001, 53, 991 .

53. Yulaev, M. F.; Sitdikov, R. A.; Dmitrieva, N. M.; Yazynina, E. V.; Zherdev, A. V.; Dzantiev, B. B.; Sens. Actuators, B 2001, 75, 129.

54. Sreedhar, N. Y.; Reddy, P. R. K.; Reddy, G. V. S.; Reddy, S. J.; Talanta 1997, 44, 1859.

55. De Souza, D.; Machado, S. A. S.; Anal. Bioanal. Chem. 2005, 382, 1720.

56. Schulze, H.; Scherbaum, E.; Anastassiades, M.; Vorlova, S.; Schmid, R. D.; Bachmann, T. T.; Biosens. Bioelectron. 2002, 17, 1095.

57. Cho, Y. A.; Seok, J.; Lee, H. S.; Kim, Y. J.; Park, Y. C.; Lee, Y. T.; Anal. Chim. Acta 2004, 522, 215.

58. Albareda-Sirvent, M.; Merkoçi, A.; Alegret, S.; Anal. Chim. Acta 2001, 442, 35.

59. Poganik, L.; Franke, M.; Biosens. Bioelectron. 1999, 14, 569.

60. Kolosova, A. Y.; Park, J. H.; Eremin, S. A.; Park, S. J.; Kang, S. J.; Shim, W. B.; Lee, H. S.; Lee, Y. T.; Chung, D. H.; Anal. Chim. Acta 2004, 511, 323.

61. Hegedüs, G.; Bélai, I.; Székács, A.; Anal. Chim. Acta 2000, 421, 121.

62. Calvo-Marzal, P.; Rosatto, S. S.; Granjeiro, P. A.; Aoyama, H.; Kubota, L. T.; Anal. Chim. Acta 2001, 441, 207.

63. Reviejo, A. J.; Gonzaléz, A.; Pingarrón, J. M.; Pólo, L. M.; Anal. Chim. Acta 1992, 264, 141.

64. Walcarius, A.; Lamberts, L.; J. Electroanal. Chem. 1996, 406, 59.

65. Hatrík, S.; Tekel, J.; J. Chromatogr., A 1996, 733, 217.

66. Midio, A. F.; Martins, D. I.; Herbicidas em alimentos, Livraria Varela: São Paulo, 1997.

67. Olek, M.; Blanchard, F.; Sudraud, G.; J. Chromatogr., A 1985, 325, 239.

68. Samatha, K.; Sreedhar, N. Y.; Talanta 1999, 49, 53.

69. Aguí, L.; Pena, L.; Pedrero, M.; Yanes-Sedeno, P.; Pingarrón, J. M.; Electroanalysis 2002, 14, 486.

70. Jin, S.; Xu, Z.; Chen, J.; Liang, X.; Wu, Y.; Qian, X.; Anal. Chim. Acta 2004, 523, 117.

71. La Rosa, C.; Pariente, F.; Hernández, L.; Lorenzo, E.; Anal. Chim. Acta 1995, 308, 129.

72. Nunes, G. S.; Skládal, P.; Yamanaka, H.; Barceló, D.; Anal. Chim. Acta 1998, 362, 59. 
73. Esteve-Turrillas, F. A.; Aman, C. S.; Pastor, A.; De la Guardiã, M.; Anal. Chim. Acta 2004, 522, 73.

74. Sorensen, S. R.; Bending, G. D.; Jacobsen, C. S.; Walker, A. J.; Microbiol. Ecol. 2003, 45, 1.

75. Pulido-Tofiño, P.; Barrero-Moreno, J. M.; Pérez-Conde, M. C.; Anal. Chim. Acta 2001, 429, 337.

76. Pulido-Tofiño, P.; Barrero-Moreno, J. M.; Pérez-Conde, M. C.; Anal. Chim. Acta 2000, 417, 85.

77. Hipólito-Moreno, A.; Leon-Gonzalez, M. E.; Perez-Ambas, L. V.; PoloDíez, L. M.; Anal. Chim. Acta 1998, 362, 187.

78. Pedrero, M.; Villena, F. J. M.; Pingarrón, J. M.; Polo, L. M.; Electroanalysis 1991, 3, 419 .

79. Pedrero, M.; Casado, B.; Villena, F. J. M.; Pingarrón, J. M.; Fresenius J. Anal. Chem. 1994, 349, 546.

80. Fernández, C.; Reviejo, A. J.; Pingarrón, J. M.; Anal. Chim. Acta 1995, 305, 192.

81. Corbine, G.; Biond, C.; Proietti, D.; Dreassi, E.; Corti, P.; Analyst 1993, $118,183$.

82. Kim, Y. J.; Cho, Y. A.; Lee, H. S.; Lee, Y. T.; Anal. Chim. Acta 2003, 494, 29.

83. Queffelec, A. L.; Boisde, F.; Larue, J. P.; Haelters, J. P.; Corbel, B.; Thouvenot, D.; Nodet, P.; J. Agric. Food Chem. 2001, 49, 1675.

84. Franck, M.; Kolá, V.; Eremim, S. A.; Anal. Chim. Acta 1995, 311, 349.

85. Turiel, B.; Fernandez, P.; Perez-Conde, C.; Gutierrez, A. M.; Câmara, C.; Talanta 1998, 47, 1255 .

86. Del Carlo, M.; Mascini, M.; Pepe, A.; Diletti, G.; Compagnone, D.; Food Chem. 2004, 84, 651.

87. Abad, A.; Moreno, M. J.; Montoya, A.; Anal. Chim. Acta 1997, 347, 103.

88. Poganik, L.; Franke, M.; Biosens. Bioelectron. 2003, 18, 1.
89. Nunes, G. S.; Barceló, D.; Grabaric, B. S.; Díaz-Cruz, J. M.; Ribeiro, M. L.; Anal. Chim. Acta 1999, 399, 37.

90. Nunes, G. S.; Marco, M. P.; Ribeiro, M. L.; Barceló, D.; J. Chromatogr., A 1998, 823, 109

91. Chuang, J. C.; Harta, K.; Chang, J. S.; Boman, L. E.; van Emon, J. M.; Reed, A. W.; Anal. Chim. Acta 2001, 444, 87.

92. Chuang, J. C.; Pollard, M. A.; Misita, M.; van Emon, J. M.; Anal. Chim. Acta 1999, 399, 135.

93. Palchetti, I.; Cagninia, A.; Del Carlo, M.; Coppi, C.; Mascini, M.; Tumerb, A. P. F.; Anal. Chim. Acta 1997, 337, 31.

94. Kolosova, A. Y.; Park, J. H.; Eremin, S. A.; Park, S. J.; Kang, S. J.; Shim, W. B.; Lee, H. S.; Lee, Y. T.; Chung, D. H.; Mercader, J. V.; Montoya, A.; Anal. Chim. Acta 1997, 347, 95.

95. Fatouros, N.; Simonin, J. P; Chevalet, J.; J. Electroanal. Chem. 1986, $213,1$.

96. Ugo, P.; Moretto, L. M.; Rudello, D.; Birriel, E.; Chevalet, J.; Electroanalysis 2001, 13, 661

97. Krulic, D.; Fatourus, N.; Chevalet, J.; J. Electroanal. Chem. 1990, 287, 215.

98. De Souza, D.; Pires, R. C.; Machado, S. A. S.; J. Braz. Chem. Soc., submetido.

99. Mann, T. L.; Krull, U. J.; Biosens. Bioelectron. 2004, 20, 945.

100. Meric, B.; Kerman, K.; Ozkan, D.; Kara, P.; Erensoy, S.; Akarca, U. S.; Mascini, M.; Osos, M.; Talanta 2002, 56, 837.

101. Wang, J.; Rivas, G.; Cai, X.; Palecek, E.; Nielsen, P.; Shiraish, H.; Dontha, N.; Luo, D.; Parrado, C.; Chicharro, M.; Farias, P. A. M.; Valera, E. S.; Grant, D. H.; Ozsoz, M.; Flair, M. N.; Anal. Chim. Acta 1997, 347, 1.

102. Kerman, K.; Meric, B.; Ozkan, D.; Kara, P.; Erdem, A.; Ozsoz, M.; Anal. Chim. Acta 2001, 450, 45.

103. Rauf, S.; Gooding, J. J.; Ghauri, M. A.; Rahman, M.; Anwar, M. A.; Khalid, A. M.; J. Pharm. Biomed. Anal. 2005, 37, 205. 